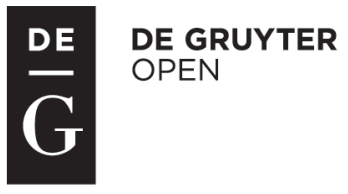

\title{
GENETIC PARAMETERS OF CONFORMATION TRAITS IN YOUNG POLISH HOLSTEIN-FRIESIAN BULLS*
}

\author{
Agnieszka Otwinowska-Mindur ${ }^{1 \star}$, Ewa Ptak ${ }^{1}$, Wojciech Jagusiak ${ }^{1}$, Andrzej Żarnecki $^{2}$ \\ ${ }^{1}$ Department of Genetics and Animal Breeding, University of Agriculture in Krakow, \\ 30-059 Kraków, al. Mickiewicza 24/28, Poland \\ ${ }^{2}$ Department of Animal Genetics and Breeding, National Research Institute of Animal Production, \\ 32-083 Balice n. Kraków, Poland \\ •Corresponding author: rzmindur@cyf-kr.edu.pl
}

\begin{abstract}
The objective of this study was to estimate the genetic parameters of conformation traits in Polish Holstein-Friesian bulls evaluated for registration in the herd book and for entry into progeny testing. Data were 8 linearly scored (1-9 scale) and 6 composite (scored from 50 to 100) conformation traits of 2,738 young bulls born between 2001 and 2011. The multiple-trait REML method was applied for (co)variance component estimation. The linear model included fixed linear regressions on age at evaluation (from 10 to 23 months), fixed effects of year of birth, fixed effects of herd-classifier, and random animal effect. Heritability estimates for all analysed traits were within the range of 0.04-0.37. Among the 6 composite type traits, heritability was highest for size and for overall conformation score. The lowest heritability was for feet and legs. Among the linearly scored traits, heritability was the lowest for rear legs - side view and foot angle, and the highest for rump angle and muscularity of front end. Composite traits showed the highest genetic correlations with muscularity and final score playing the dominant role. Genetic correlations among linear traits were low and moderate $(0.02-0.53)$. The relatively low genetic and phenotypic correlations indicated that no conformation trait of bulls can be improved by indirect selection alone. More research is needed to establish relationship between bull conformation traits and the conformation of their progeny.
\end{abstract}

Key words: conformation traits, young bulls, genetic parameters

Effective selection of the best bulls for use as sires is a key to genetic improvement of dairy herds. Recently, in most breeding programmes young bulls have been preselected based on genomic evaluations and then progeny-tested. Genomic selection can be used to predict breeding values for animals without phenotype data. Thus,

*Supported by Polish Ministry of Science and Higher Education (funds for statutory activity, DS 3228). 
selection decisions in dairy cattle can be made for young animals. This is important for breeding schemes; young bulls with no progeny can be selected as sires, whereas in conventional breeding systems they must wait for phenotypic records of their daughters and this typically takes 5-6 years (Pryce and Daetwyler, 2012). The progeny testing scheme provides relatively high accuracy of breeding value estimations but the long generation interval hampers genetic progress (Meuwissen and Goddard, 1997; Powell et al., 2003). Evaluation of young bulls with relatively high accuracy and earlier selection would shorten the generation interval and decrease the costs of maintaining undesired bulls (Reinhardt et al., 2005). The bulls' own conformation can be used as a good source of information in selection if traits measured in both sires and their daughters show substantial genetic correlations. The breeding value of a sire for a particular trait is evaluated based on his daughters' expression for this trait. This procedure significantly lengthens the generation interval and might produce cattle with undesirable characteristics unless the unfavourable genes of a bull are detected beforehand (Boelling et al., $2001 \mathrm{~b}$ ).

In the last two decades, conformation has become a very important component of breeding and selection decisions in dairy cattle populations. Besides udder diseases, and fertility problems, foot and leg disorders are the most frequent culling reasons in dairy herds, so these traits have been gaining more and more attention from farmers (Boelling et al., 2001 a; Reinhardt et al., 2005). The need to improve feet and legs of dairy cows is stressed by many authors, since lameness has become an important disease (Boelling et al., 2001 b). Reinhardt et al. (2005) concluded that routine recording and evaluation of claw data offers an opportunity to improve foot and leg health and consequently functional longevity in dairy populations.

In Poland, type traits are evaluated both in male and in female populations. Young bulls' scores are used as an early selection criterion before entering progeny testing; the scores help to choose better bulls as future sires and in consequence to predict the longevity of their future daughters. The objective of this study was to examine the possibility of using bulls' own conformation scores in the breeding value evaluation system, by estimating heritabilities and the genetic and phenotypic correlations of the type scores measured in young males before entering progeny test.

\section{Material and methods}

Data were obtained from the Polish Federation of Cattle Breeders and Dairy Farmers and included 14 conformation traits of 2,738 Polish Holstein-Friesian young bulls: 6 composite and 8 linearly scored traits. The composite traits were evaluated using a system of scoring on a scale from 50 to 100 points, and the linear traits were scored on a 9-point scale (Table 1).

The young bulls were scored by 23 classifiers in 104 herds. They were evaluated at the age of 10 to 23 months as required for registration in the herd book and for entry into progeny testing. The bulls were born between 2001 and 2011 and were sons of 144 sires. Two restrictions were imposed on the data: a minimum of 5 sons per sire, and a minimum of 4 contemporaries per herd-classifier subclass. 
Table 1. Description of the linear type traits

\begin{tabular}{l|c|c|c}
\hline \multicolumn{1}{c}{ Trait } & Score 1 & Score 9 & Ideal score \\
\hline Body depth & Shallow & Deep & 9 \\
Chest width & Narrow & Wide & 9 \\
Rump angle & High pins & Low pins & 5 \\
Rump width & Narrow pins & Wide pins & 9 \\
Rear legs - side view & Straight & Slicked & 5 \\
Foot angle & Low & Steep & 9 \\
Rear legs - rear view & Toes out & Parallel bow-legged & 9 \\
Muscularity of front end & Sharp & Coarse & 5 \\
\hline
\end{tabular}

The multiple-trait REML method was applied using the BLUPF90 computing package for (co)variance component estimation (Misztal, 2008). The linear model for each of 14 conformation traits was as follows:

$$
y=X b+Z u+e
$$

where:

$y$ is the vector of observations (conformation scores),

$b$ is the vector of fixed effects: herd-classifier (131 levels), year of birth (11 levels) and linear regression on age at evaluation (10-23 months),

$u$ is the vector of additive animal genetic effects (5,172 levels),

$e$ is the vector of residual error.

Matrices $X$ and $Z$ relate observations to effects. Matrix $G=A^{-1} G_{0}$, where $A^{-1}$ is the numerator relationship matrix and $\mathrm{G}_{0}$ is the genetic (co)variance matrix between traits. It was assumed that $\mathrm{E}(\mathrm{u})=0, \mathrm{E}(\mathrm{e})=0, \mathrm{~V}(\mathrm{u})=\mathrm{G}, \mathrm{V}(\mathrm{e})=\mathrm{R}, \operatorname{Cov}(\mathrm{u}, \mathrm{e})=0, \mathrm{E}(\mathrm{y})=\mathrm{Xb}$, and $\mathrm{V}(\mathrm{y})=\mathrm{ZGZ}+\mathrm{R}$. Matrix $\mathrm{R}=\mathrm{I} \otimes \mathrm{R}_{0}$, where $\mathrm{R}_{0}$ is the residual (co)variance matrix between traits and $\otimes$ is the Kronecker product. The assumed convergence criterion is $1 \times 10^{-10}$. Standard deviations of the parameters were calculated based on the negative inverse of the average information matrix from AIREML.

\section{Results}

Descriptive statistics and heritabilities for conformation traits are presented in Table 2. Among the composite type traits, size showed the highest mean and the largest coefficient of variability, whereas feet and legs had the lowest mean. The means of other composite traits were in the range of 81.93-83.11 ( $\mathrm{SD}=2.27-2.59)$. Among linearly scored traits the mean values ranged from 4.61 to 6.80 . The average scores for most linear type traits were close to the middle of the scale. For some traits the 
desired scores were around 5 points or slightly higher (rear legs - side view, rump angle) and for others close to 9 (rear legs - rear view, chest width). Rear legs - rear view showed the largest difference between the mean (5.3) and desired score (9.0) but the variability of this trait $(\mathrm{SD}=1.32 ; \mathrm{CV}=24.9 \%)$ was the highest among the linearly scored traits. Average scores for foot angle (5.68) and rump width (5.48) also differed from the assumed optimum (9.0). For most linear traits, values of 1, 2 or 9, corresponding to biological extremes, occurred rarely (less than $1.5 \%$ of all records) except for rump angle, for which $3.2 \%$ of the bulls had values of 1,2 or 9 . One of the reasons to use a shorter scale could be the lack of experience of some classifiers. Generally, linearly scored traits showed higher variation than composite traits (CV for linear traits: $13-24.9 \%$; CV for composite traits: $2.7-5.1 \%$ ).

For all analysed traits the heritability (Table 2) estimates were low to moderate (0.04-0.37). Among the 6 composite traits the most heritable ones were size $(0.37)$ and overall conformation score ( 0.31$)$; heritability estimated for feet and legs was the lowest (0.10). Among linearly scored traits, heritabilities obtained for leg traits were generally low (from 0.04 for rear legs - side view to 0.15 for rear legs rear view); estimated heritability was highest for rump angle (0.31) and muscularity of front end (0.24). Standard deviations for heritabilities were between 0.007 and 0.024 .

Table 2. Means $(\overline{\mathrm{x}})$, standard deviations (SD), coefficients of variation (CV), ranges (Min, Max) and heritabilities $\left(h^{2}\right)$ of conformation traits $(n=2,738$ tested bulls)

\begin{tabular}{l|l|c|c|c|c|c|c}
\hline No. & \multicolumn{1}{c|}{ Composite traits } & $\overline{\mathrm{x}}$ & $\mathrm{SD}$ & $\mathrm{CV}(\%)$ & $\mathrm{Min}$ & $\mathrm{Max}$ & $\mathrm{h}^{2}(\mathrm{SD})$ \\
\hline 1 & General appearance & 82.80 & 2.59 & 3.1 & 69 & 90 & $0.28(0.024)$ \\
2 & Size & 85.07 & 4.38 & 5.1 & 69 & 96 & $0.37(0.019)$ \\
3 & Overall conformation score & 83.11 & 2.56 & 3.1 & 69 & 96 & $0.31(0.020)$ \\
4 & Feet and legs & 81.60 & 2.75 & 3.4 & 67 & 90 & $0.10(0.013)$ \\
5 & Muscularity & 81.93 & 2.50 & 3.1 & 69 & 90 & $0.16(0.017)$ \\
6 & Final score & 82.90 & 2.27 & 2.7 & 69 & 89 & $0.28(0.020)$ \\
\hline No. & $\quad$ Linearly scored traits & $\overline{\mathrm{x}}$ & $\mathrm{SD}$ & $\mathrm{CV}(\%)$ & $\mathrm{Min}$ & $\mathrm{Max}$ & $\mathrm{h}^{2}(\mathrm{SD})$ \\
\hline 7 & Body depth & 6.49 & 0.98 & 15.0 & 1 & 9 & $0.19(0.022)$ \\
8 & Chest width & 6.02 & 1.03 & 17.2 & 2 & 9 & $0.12(0.018)$ \\
9 & Rump angle & 4.61 & 1.11 & 24.0 & 1 & 9 & $0.31(0.024)$ \\
10 & Rump width & 5.48 & 1.09 & 19.9 & 2 & 9 & $0.13(0.019)$ \\
11 & Rear legs - side view & 5.32 & 0.79 & 14.8 & 2 & 8 & $0.04(0.007)$ \\
12 & Foot angle & 5.68 & 1.08 & 19.1 & 1 & 9 & $0.11(0.016)$ \\
13 & Rear legs - rear view & 5.31 & 1.32 & 24.9 & 2 & 9 & $0.15(0.018)$ \\
14 & Muscularity of front end & 6.80 & 0.88 & 13.0 & 2 & 9 & $0.24(0.021)$ \\
\hline
\end{tabular}


Table 3 shows the genetic and phenotypic correlations of 14 conformation traits of young bulls. Composite traits showed relatively high genetic correlations; all were positive except for the correlation between size and feet and legs $(-0.09)$. The genetic correlations between final score and other composite traits were positive and high except for a moderate correlation between final score and feet and legs (0.31). Generally, feet and legs was the trait with the weakest genetic relationship with other composite traits.

The genetic correlations among linear traits were low to moderate: from 0.02 to 0.53 , regardless of sign. Chest width was moderately and positively correlated with other linear traits (from 0.02 with rear legs - side view to 0.47 with rump width), except for a negative correlation with muscularity of front end (-0.29). Among the linear type traits, rump angle and rump width showed the strongest genetic relationship (0.53), whereas the relationship of these two traits with rear legs - side view was very weak ( 0.02 and 0.07 , respectively), as was the correlation between rump angle and rear legs - rear view $(-0.07)$. The genetic correlations between composite and linearly scored traits were low to moderate, except for relatively high correlations between composite traits and muscularity of front end (from 0.38 with feet and legs to 0.85 with general appearance and 0.89 with overall conformation score). Rear legs - side view, rear legs - rear view, and body depth were negatively correlated with almost all composite traits $(-0.15$ to -0.53$)$.

The phenotypic correlations among composite conformation traits were positive, from moderate to high, and lower than the genetic ones. They ranged from 0.19 (between size and feet and legs) to 0.89 (between general appearance and final score). Final score was a linear combination of all other composite traits, so it was favourably associated with all of them (0.60-0.89). Among the remaining composite traits, the phenotypic relationship was highest between general appearance and overall conformation score $(0.85)$.

The phenotypic correlations among linearly scored traits were generally lower (ignoring sign) than among composite traits. Rump angle was not phenotypically correlated with foot angle $(0.00)$ and chest width $(-0.01)$, as were the phenotypic correlations between chest width and muscularity of front end $(0.00)$. The correlations between rump angle and the other linear traits were close to zero ( -0.05 to 0.06$)$. Almost all phenotypic correlations between composite and linearly scored traits were moderate or close to zero. Rear legs - side view was negatively and weakly correlated with all 6 composite traits. As in the case of genetic correlations, muscularity of front end showed the highest phenotypic relationships, mainly with overall conformation score $(0.71)$, general appearance $(0.60)$ and final score $(0.57)$. 


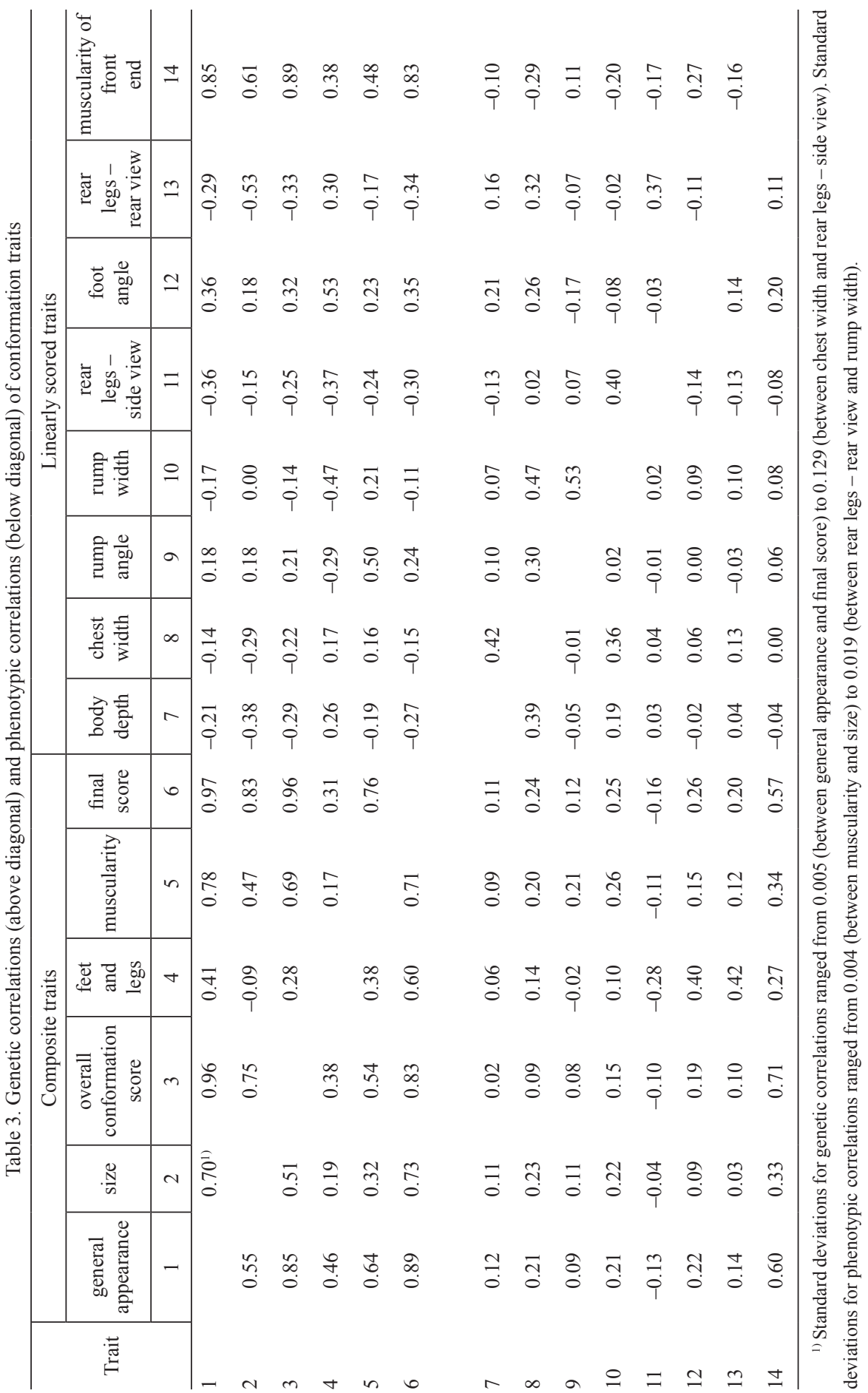




\section{Discussion}

The literature on genetic parameters for type traits of young bulls is sparse (Boelling et al., 2001 b; Reinhardt et al., 2005; Topolski, 2011). In Germany, claw and leg traits have been collected for young bulls since 1996, and since 2004 the data have been used for genetic evaluation. The proofs obtained have been used as predictors for longevity of future daughters of bulls (Reinhardt et al., 2005). Boelling et al. (2001 a, b) also studied foot and leg traits in Danish cattle populations but the purpose of their research was to correlate traits measured in young bulls with traits of their daughters. In the Polish breeding scheme, conformation traits scored for young bulls have been used only as an early selection criterion for bulls, and genetic evaluation of sires for type traits is still based on data collected from their daughters (PFHBiPM, 2014).

In the case of composite traits, the higher the score, the better the merit of the bull. Composite scores for Polish bulls show that their conformation corresponds well with the conformation standard. Topolski (2011) also found that the means for composite traits of Polish young bulls born between 2000 and 2007 were high (above 80 points); in that study the highest average was for size (83.92) and the lowest was for feet and legs (81.28), in agreement with our findings. Means of most composite traits scored for young bulls in our study were higher than means obtained for cows (Ptak et al., 2011; Zavadilová and Štípková, 2012).

For most linear traits, Polish classifiers did not use the full scale of points, and none of the bulls received score 1; for rear legs - side view an even shorter scale was used (from 2 to 8). Reinhardt et al. (2005) noted that German classifiers also rarely used extreme scores, perhaps due to classifiers' lack of experience or perhaps because the candidate bulls were close to the conformation standard as they were highly preselected and kept in optimal environmental conditions. Topolski (2011) reported that Polish classifiers gave extreme scores more often than German ones did, but only for the group of younger animals.

The mean values for linear traits found by Topolski (2011) were in the range of 4.79-6.58, in agreement with results of the present study. The means for rear legs - rear view (5.26) and foot angle (5.73), that is, traits with the largest deviation from the most desirable values, were also similar to the present results. In view of the dearth of literature on bull conformation traits, to make a comparison we referred our findings to results given for cow populations. Zavadilová and Štípková (2012) published lower mean values for both body depth and chest width (5.80) in the Czech cow population. Ptak et al. (2011) also estimated relatively low means for these two traits in Polish Holstein-Friesian cows (6.11 for body depth and 5.41 for chest width). Those results indicate that for body depth and chest width bulls were scored higher than cows. In the Czech cow population the means for two rump traits (rump angle and rump width) and for the three leg traits (rear legs - side view, rear legs - rear view, and foot angle) were similar to our averages (Zavadilová and Štípková, 2012). The means for rump width and rear legs - side view of young bulls were also consistent with estimates published by Ptak et al. (2009) for Polish Holstein-Friesian cows; the means for foot angle (5.24) and rear legs - 
rear view (4.69) were lower, whereas for rump angle the mean was higher (5.27).

All heritability estimates for type traits of young bulls were low to moderate (0.04-0.37) and were slightly lower but in many cases consistent with those reported by Topolski (2011), who noted that among the composite traits the highest heritability estimates were for size (0.61), overall conformation score $(0.31)$ and final score (0.30), and the lowest for feet and legs (0.19). Our results trended similarly but we found much lower heritability for size $(0.37)$. Among the linearly scored traits, Topolski (2011) found that leg traits were the least heritable: rear legs - side view (0.13), foot angle (0.19) and rear legs - rear view (0.19). Body depth (0.42) was the most heritable in that work. Those estimates, like previous ones, were higher than ours, especially for body depth and rear legs - side view. In young bulls, Reinhardt et al. (2005) reported much higher heritability for rear legs - side view (0.23) and slightly lower heritability for rear legs - rear view (0.11).

In most cases the heritabilities for bulls are in ranges similar to those for cow populations (Żarnecki et al., 2003; Berry et al., 2004; Ptak et al., 2009, 2011; Zavadilová and Štípková, 2012). Among composite traits scored in cows the least heritable were feet and legs: $0.12-0.13$ by Zavadilová and Štípková (2012), 0.11 by Żarnecki et al. (2003), and 0.11 by Ptak et al. (2011). Three leg traits showed the lowest heritability (0.07-0.14) among linear traits (Ptak et al., 2011; Zavadilová and Štípková, 2012). Our results and those of other authors confirm that leg traits for both sexes are strongly influenced by environmental conditions and are difficult to improve by selection.

On the other hand, selection might be an efficient method to improve size and overall conformation score. In cows, Ptak et al. (2011) reported heritabilities of 0.39 and 0.30 respectively for these traits, and Żarnecki et al. (2003) reported 0.42 and 0.29 . Among linear traits, the most heritable trait in bulls was rump angle (0.31); its heritability was also high in cows: 0.31 (Zavadilová and Štípková, 2012) and 0.29 (Ptak et al., 2011).

Generally the genetic correlations were higher than the phenotypic ones (Table 3), comparable with those estimated by Topolski (2011) for Polish young bulls, but different from those calculated for type traits of Polish cows by Żarnecki et al. (2003) and Ptak et al. (2009). Topolski (2011) reported the lowest genetic correlations between feet and legs and the other composite traits (0.01-0.38), and much higher genetic correlations among other composite traits (0.56-0.97). He remarked that the genetic correlations between pairs of composite traits were positive and in most cases relatively high, justifying simultaneous improvement of the most important bull conformation traits. Our results confirm his finding although some of the values for genetic correlations differed slightly from his results (e.g., between feet and legs and size).

As shown in our study, body depth presented a favourable genetic relationship with both composite and linear leg traits. The negative correlation between body depth and rear legs - side view also refers to a desirable relationship because it means that deep body is rarely associated with sickled legs. Other genetic correlations of body depth with composite traits and some linear traits of Polish young bulls 
were negative; for example, deep body of bulls was weakly related to the conformation standard, confirming results obtained by Topolski (2011).

Two linear traits related to rump (rump angle and rump width) were highly genetically correlated $(0.53)$ and showed low genetic correlations with composite and linear traits except for the correlation between rump angle and composite muscularity (0.50). The relatively large correlation was probably the result of the fact that muscularity was scored based on rear parts of the bull body. Rump width showed a positive correlation with rear legs - side view (0.40) and no correlation with rear legs - rear view $(-0.02)$. The former correlation suggested that daughters of bulls with a wide rump were more often expected to have sickled legs. Opposite relationships were reported by Topolski (2011): -0.19 between rump width and rear legs side view and 0.54 between rump width and rear legs - rear view.

Rear legs - side view was negatively genetically correlated with all composite traits, likely the result of the intermediate optimum assumed for this trait. Rear legs - rear view and foot angle, for which a higher score is generally more favourable, showed genetic correlations with most composite traits similar in value but opposite in sign. The highest negative correlation was between rear legs - rear view and size $(-0.53)$, indicating that large and heavy bulls might transmit undesirable rear leg set to their daughters.

Muscularity of front end plays an important role in the conformation standard for the breed, as confirmed by the low correlation with other linear traits but the strong and positive correlation with all composite traits.

The genetic relationships among conformation traits in bull and cow populations differed in both value and sign, especially in the case of linear traits (Żarnecki et al., 2003). This might mean that the phenotypes of type traits in males and females were determined by different genes.

The phenotypic correlations for conformation traits were consistent with those reported by Topolski (2011) in the young bull population and also with results from Żarnecki et al. (2003) and Ptak et al. (2009) for cows. Final score as a linear combination of all other composite traits showed high phenotypic correlations with all of them. Among the linear traits, muscularity of front end, foot angle, and rump and chest width were correlated mostly with final score, in agreement with Topolski (2011).

This detailed examination of genetic and phenotypic correlations indicates that no conformation trait of bulls can be improved solely by indirect selection for other traits. All analysed traits should be scored and used in selecting young bulls for sires. The genetic relationships in the male population differed markedly from those in females. It is worth examining whether there is a relationship between bulls' conformation traits and the conformation of their progeny.

Currently, genomically enhanced breeding value (GEBV) is computed based on two components: direct genomic value and pedigree index. GEBV is still less accurate than breeding value estimated based on progeny tests. Including the breeding value of young bulls as estimated using their own phenotypes, as the third part of GEVB, might substantially increase its accuracy. 


\section{References}

B erry D.P., B u ckley F., Dillon P., Evan s R.D., Ve erka m p R.F. (2004). Genetic relationships among linear type traits, milk yield, body weight, fertility and somatic cell count in primiparous dairy cows. Irish J. Agr. Food Res., 43: 161-176.

B o e 11 ing D., Mads en P., Jensen J. (2001 a). Genetic parameters of foot and leg traits in future AI bulls: I. Influence of age at recording and classifier. Acta Agr. Scand. A-An., 51: 114-121.

B oelling D., Madsen P., Jensen J. (2001 b). Genetic parameters of foot and leg traits in future AI bulls: II. Correlation to body conformation traits in daughter. Acta Agr. Scand. A-An., 51: $122-128$.

L a w s tu e n D., H a n s e n L., J o h n s o n L. (1987). Inheritance and relationships of linear composite type traits for age groups of Holsteins. J. Dairy Sci., 70: 1027-1035.

M e u w is s e n T.H.E., G o d d a r d M.E. (1997). Optimization of progeny tests with prior information on young bulls. Livest. Prod. Sci., 52: 57-68.

M i s z t a 1 I. (2008). Reliable computing in estimation of variance components. J. Anim. Breed. Genet., 125: $363-370$.

PFHBiPM (2014). Rules for entry of Polish Holstein-Friesian cattle in the Herd Book (in Polish). www. pfhb.pl/hodowla_2012/regulamin_rasy_polskiej_hf.pdf

P ow ell R.L., N orm a n H.D., S a n d e r s A.H. (2003). Progeny testing and selection intensity for Holstein bulls in different countries. J. Dairy Sci., 86: 3386-3393.

Ptak E., Jagusiak W., Żarnecki A., Otwinowska-Mindur A. (2009). Genetic parameters of daily somatic cell score and some conformation traits in Polish Holstein cattle. Ann. Anim. Sci., 9: 355-361.

Ptak E., Jagus iak W., Żarnecki A., Otwinowska-Mindur A. (2011). Heritabilities and genetic correlations of lactational and daily somatic cell score with conformation traits in Polish Holstein cattle. Czech J. Anim. Sci., 56: 205-212.

Pry c e J.E., D a e tw y l e r H.D. (2012). Designing dairy cattle breeding schemes under genomic selection: a review of international research. Anim. Prod. Sci., 52: 107-114

Reinhardt F., Ruten W., Rens ing S. (2005). Genetic evaluation for feet traits collected from young German Holstein bulls. Interbull Bull., 33: 167-170.

To p o ls k i P. (2011). Genetic analysis of conformation traits in Polish Holstein-Friesian bulls of Blackand-White variety (in Polish). PhD Thesis. Instytut Zootechniki PIB, 83 pp.

Z a vadilová L., Š tí p k ová M. (2012). Genetic correlations between longevity and conformation traits in the Czech Holstein population. Czech J. Anim. Sci., 57: 125-136.

Żarnecki A., M or ek-Kopeć M., J a g u s i a k W. (2003). Genetic parameters of linearly scored conformation traits of Polish Black-and-White cows. J. Anim. Feed Sci., 12: 689-696.

Received: 12 V 2014

Accepted: 19 VIII 2014 